Audiology

Neurotology
Audiol Neurotol 2012;17:179-188

DOI: $\underline{10.1159 / 000335657}$
Received: October 10, 2011

Accepted after revision: December 6, 2011

Published online: January 31, 2012

\title{
Reduction of Tinnitus Severity by the Centrally Acting Muscle Relaxant Cyclobenzaprine: An Open-Label Pilot Study
}

\author{
Claudia Coelho ${ }^{a, b}$ Ricardo Figueiredo ${ }^{c}$ Elmar Frank ${ }^{d}$ Julia Burger ${ }^{d}$ \\ Martin Schecklmann ${ }^{d}$ Michael Landgrebe ${ }^{d}$ Berthold Langguth ${ }^{d}$ \\ Ana Belen Elgoyhen ${ }^{\mathrm{e}}$ \\ ${ }^{a}$ Department of Otolaryngoly and Head and Neck Surgery, University of lowa, lowa City, lowa, USA; ${ }^{b}$ Grupo de \\ Pesquisa em Otoneurologia, Departamento de Otorrinolaringologia, Faculdade de Medicina, Universidade Federal \\ do Rio Grande do Sul, Porto Alegre, and ' OTOSUL, Clinical and Research Tinnitus Center, Volta Redonda, Brazil; \\ dInterdisciplinary Tinnitus Clinic and Department of Psychiatry and Psychotherapy, University of Regensburg, \\ Regensburg, Germany; ' Instituto de Investigaciones en Ingeniería Genética y Biología Molecular, Consejo Nacional \\ de Investigaciones Científicas y Técnicas, Tercera Cátedra de Farmacología, Facultad de Medicina, Universidad de \\ Buenos Aires, Buenos Aires, Argentina
}

\section{Key Words}

Tinnitus - Phantom perception - Somatosensory system •

Muscle relaxants

\begin{abstract}
Tinnitus, the phantom perception of sounds, is a highly prevalent disorder. Although a wide variety of drugs have been investigated off label for the treatment of tinnitus, there is no approved pharmacotherapy. We report an open-label exploratory pilot study to assess the effect of muscle relaxants acting on the central nervous system on tinnitus patients. Cyclobenzaprine at high (30 mg) and low doses (10 mg), orphenadrine (100 mg), tizanidine ( $24 \mathrm{mg}$ ) and eperisone (50 $\mathrm{mg}$ ) were administered to a maximum of 20 patients per group over a 12-week period. High-dose cyclobenzaprine resulted in a significant reduction in the Tinnitus Handicap Inventory (THI) score between baseline and week 12 in the intention-to-treat sample. On the other hand, other treatments were not effective. These results were confirmed in an explorative analysis where baseline corrected THI and Clini-
\end{abstract}

cal Global Impression scores at week 12 were compared between groups. The present open trial presents a new promising pharmacotherapy for tinnitus that should be validated in placebo-controlled double-blind trials.

Copyright $\odot 2012$ S. Karger AG, Basel

\section{Introduction}

Tinnitus is a phantom phenomenon in which a patient has a conscious hearing perception that can take the form of ringing, buzzing, roaring or hissing (among others) in the absence of an external sound [Eggermont and Roberts, 2004; Moller, 2007a]. Many people have experienced ringing in their ears when no external sound is present [Moller, 2007a]. However, in 5-15\% of the general population, the tinnitus sensation is unremitting [Eggermont and Roberts, 2004]. It is estimated that for 1 in 100 of the general population, the condition severely affects their quality of life, since it is accompanied by a variety of symptoms including hyperacusis (lowered tolerance to

\section{KARGER}

Fax +41613061234 E-Mail karger@karger.ch www.karger.com
(C) 2012 S. Karger AG, Basel

$1420-3030 / 12 / 0173-0179 \$ 38.00 / 0$

Accessible online at:

www.karger.com/aud
Ana Belén Elgoyhen

Instituto de Investigaciones en Ingeniería Genética y Biología Molecula

Vuelta de Obligado 2490

1428 Buenos Aires (Argentina)

Tel. +54 114783 2871, E-Mail abelgoyhen@gmail.com 
sound), phonophobia (fear of sound), anxiety, depression, irritability, agitation, stress, insomnia and even leading to suicide attempts in severe cases [Moller, 2007a].

The available treatments for the management of the tinnitus patient are diverse and for most of them some patients benefit to some degree [Darlington and Smith, 2007; Dobie, 1999; Dohrmann et al., 2007; Elgoyhen and Langguth, 2010; Goodey, 2007; Jastreboff and Jastreboff, 2006; Langguth et al., 2006; Langguth et al., 2009; Patterson and Balough, 2006; Van de Heyning et al., 2008]. However, any particular treatment does not benefit all patients, most likely due to different underlying pathophysiologies. In addition, some fraction of patients is left untreated. Thus, tinnitus is still today a clinically unmet need, and many patients would welcome a drug which reduces or even abolishes their phantom sound. Although over 4 million prescriptions are written each year for tinnitus relief in Europe and the USA, these are all off-label prescriptions from a wide variety of therapeutic drugs, and there is currently not a single FDAor EMA-approved drug on the market [Elgoyhen and Langguth, 2010; Langguth et al., 2009; Vio and Holme, 2005].

Tinnitus is a symptom that is associated with virtually all diseases and disorders affecting the auditory system and can arise from a lesion in any part of the auditory pathway. While the initial lesion might affect the peripheral organ of the auditory system, the neural correlate of the sound perceived is most likely in the central nervous system [Eggermont and Roberts, 2004]. Although the mechanisms underlying tinnitus are far from being fully understood, there is growing evidence that changes in neuronal activity, neuronal synchrony, disruption of the balance between excitation and inhibition and rearrangements of the tonotopic organization in different parts of the auditory pathway, including the dorsal cochlear nucleus, inferior colliculus, thalamus and/or auditory cortex, underlie tinnitus pathology [Bauer et al., 2008; Eggermont and Roberts, 2004; Kaltenbach and Godfrey, 2008; Melcher et al., 2000; Schlee et al., 2009a; Smits et al., 2007]. Moreover, tinnitus is not a static condition and probably involves multiple dynamic brain networks, which extend beyond the primary sensory cortices [De Ridder et al., 2011; Schlee et al., 2008, 2009a, b]. Faced with this lack of deep understanding of the pathophysiology of tinnitus, a priori any drug acting on the nervous system becomes a potential compound to be tried in tinnitus patients. A considerable number of drugs have been evaluated in clinical trials [Elgoyhen and Langguth, 2010; Langguth et al., 2009; Vio and Holme, 2005].
Although some subgroups of patients present positive results, they are not always clearly identified and most trials have demonstrated no replicable long-term reduction of tinnitus in most of the patients, with an effect superior to placebo [Dobie, 1999; Elgoyhen and Langguth, 2010; Langguth et al., 2009]. In the absence of effective tools towards identifying subgroups of patients to be included in well-designed placebo-controlled clinical trials, an open-trial design should be considered as a prior step [Dobie, 1999; Landgrebe et al., 2011a].

The aim of the present work was to analyze and compare the effect of several centrally acting muscle-relaxant drugs on tinnitus patients: cyclobenzaprine, orphenadrine, tizanidine and eperisone. These compounds were chosen since either there exist no previous reports for their use in tinnitus (cyclobenzaprine and tizanidine) or just isolated cases (orphenadrine [Abdul-Baqi, 2004] and eperisone [Murai et al., 1992]) have been published. Moreover, they all have a central nervous system mechanism of action and have been used in the treatment of different forms of pain [Cabitza and Randelli, 2008; Chau et al., 1998; Desaphy et al., 2009; Hunskaar and Donnell, 1991; Ishizuki and Yanagisawa, 1992; Kino et al., 2005; Kobayashi et al., 1996; Kornhuber et al., 1995; Leite et al., 2009; Sayers et al., 1980; Yang et al., 2011], a disorder that has some striking pathophysiological similarities with tinnitus [De Ridder et al., 2011; Moller, 2007b].

\section{Patients and Methods}

Five different treatments were offered to patients attending tinnitus clinics in Lajeado, Brazil (orphenadrine, tizanidine, high-dose cyclobenzaprine) and Regensburg, Germany (low-dose cyclobenzaprine, eperisone). Subjects enrolled between February 2008 and March 2010 were screened according to general inclusion and exclusion criteria as indicated in table 1 . Additional specific criteria for each treatment are given in table 2. Subjects enrolled were clinical patients seeking help because of their tinnitus who were informed of their option to participate in the study.

Patients were informed about the nature, purpose and potential risks of this individualized healing attempt and gave written informed consent to this procedure, which was performed according to the declaration of Helsinki. Patient data was kept confidential throughout all further analyses, which have been approved by the local ethics committee (Ethikkommission an der Universität Regensburg).

Prospective assessment of treatment effects was performed using standardized procedures as established in the Tinnitus Research Initiative database [Landgrebe et al., 2011b]. This follows the consensus for patient assessment and outcome measurement found by tinnitus experts from many countries during an international tinnitus conference in Regensburg, Germany in 2006 [Langguth et al., 2007]. The core assessments consisted of a stan- 
Table 1. General inclusion and exclusion criteria

\begin{tabular}{ll}
\hline Inclusion criteria & General exclusion criteria \\
\hline $\begin{array}{l}\text { Primary complaints of chronic } \\
\text { tinnitus }>5 \text { months }\end{array}$ & Treatable otological disorder \\
\hline Age between 18 and 75 years & $\begin{array}{l}\text { Serious or unstable medical } \\
\text { or psychiatric condition }\end{array}$ \\
\hline $\begin{array}{l}\text { Tinnitus Handicap Inventory } \\
\text { scores at screening } \geq 20\end{array}$ & Pregnancy or breast-feeding \\
$\begin{array}{l}\text { Normal magnetic resonance } \\
\text { imaging of the pontine angle in the } \\
\text { presence of unilateral tinnitus or } \\
\text { asymmetric hearing thresholds }\end{array}$ & Alcohol or drug abuse \\
\hline $\begin{array}{l}\text { Willingness to receive the pro- } \\
\text { posed drug as treatment and } \\
\text { to complete the assessments }\end{array}$ & $\begin{array}{l}\text { Hypersensitivity to the } \\
\text { medication or any } \\
\text { component of the product }\end{array}$ \\
\hline
\end{tabular}

Table 2. Specific exclusion criteria for each compound

\begin{tabular}{ll}
\hline Compound & Exclusion criteria \\
\hline Orphenadrine & $\begin{array}{l}\text { Cardiospasm, glaucoma, myasthenia gravis, } \\
\text { prostatic hypertrophy or obstruction of bladder } \\
\text { neck, pyloric or duodenal obstruction, stenos- } \\
\text { ing peptic ulcer, cardiac arrhythmias and/or } \\
\text { decompensation, coronary insufficiency, } \\
\text { tachycardia, concomitant use of propoxyphene }\end{array}$ \\
\hline Tizanidine & $\begin{array}{l}\text { Concomitant use of ciprofloxacin, fluvoxamine, } \\
\text { CYP1A2 inhibitors and antihypertensive } \\
\text { therapy, liver and renal impairment }\end{array}$ \\
\hline $\begin{array}{l}\text { Cyclo- } \\
\text { benzaprine }\end{array}$ & $\begin{array}{l}\text { Cardiac problems, arrhythmias, cardiac con- } \\
\text { duction disturbances, heart block, congestive } \\
\text { heart failure and myocardial infarction within } \\
\text { 1 year of study, hyperthyroidism, glaucoma, } \\
\text { concomitant use of monoaminoxidase inhibi- } \\
\text { tors, hepatic impairment and urinary retention }\end{array}$ \\
\hline Eperisone & \begin{tabular}{l} 
Hepatic impairment \\
\hline
\end{tabular}
\end{tabular}

Table 3. Treatment schedule (mg/day)

\begin{tabular}{lrrrrrrrrr}
\hline Medication & Week 1 & Week 2 & Week 3 & Week 4 & Weeks 5-11 & Week 12 & Week 13 & Week 14 & Weeks 15-16 \\
\hline Orphenadrine & 100 & 100 & 200 & 200 & 200 & 200 & 100 & 100 & - \\
Tizanidine & 8 & 12 & 16 & 24 & 24 & 16 & 12 & 8 & - \\
Cyclobenzaprine (high dose) & 15 & 15 & 22.5 & 30 & 30 & 30 & 22.5 & 15 & - \\
Cyclobenzaprine (low dose) & 10 & 10 & 10 & 10 & 10 & 10 & - & - & - \\
Eperisone & 50 & 50 & 50 & 50 & 50 & 50 & - & - & - \\
\hline
\end{tabular}

dardized detailed tinnitus and medical history (Tinnitus Sample Case History Questionnaire), otological examination, psychoacoustic measures of tinnitus (pitch match and minimal masking level), a validated questionnaire for the assessment of tinnitus severity (Tinnitus Handicap Inventory, THI), and the subjective Clinical Global Impression score (CGI). Hearing thresholds were performed at $500 \mathrm{~Hz}, 1,2,3$ and $4 \mathrm{kHz}$. In patients with asymmetric hearing loss and/or unilateral tinnitus, the presence of a tumor was excluded by magnetic resonance imaging. Treatment duration was 12-14 weeks (table 3). Patients were assessed at weeks 2, 4, 8, 12 and 16 with the THI, CGI and clinically monitored for the presence of adverse effects. When moderate to severe side effects were observed, patients were removed from the trial. Tinnitus pitch and minimal masking level were repeated at week 12 in a subgroup of patients. In the orphenadrine, tizanidine and high-dose cyclobenzaprine groups, medication was uptitrated over the first 4 weeks in order to reduce possible side effects, and then downtitrated from week 12 to 14 , so as to prevent rebounds. Dose regimens for the different groups are indicated in table 3.
Table 4. Number of subjects screened, allocated to treatment and completing treatment

\begin{tabular}{llllr}
\hline Drug trial & $\begin{array}{c}\text { Screened } \\
\text { Allocated } \\
\text { to treat- } \\
\text { ment }\end{array}$ & $\begin{array}{l}\text { Dropped Com- } \\
\text { out }\end{array}$ & $\begin{array}{l}\text { Coted } \\
\text { the trial }\end{array}$ \\
\hline $\begin{array}{l}\text { Orphenadrine } \\
\text { Tizanidine }\end{array}$ & 35 & 18 & $6(5)$ & 12 \\
Cyclobenzaprine (high dose) & 30 & 11 & $8(4)$ & 3 \\
Cyclobenzaprine (low dose) & 16 & 15 & $1(1)$ & 14 \\
Eperisone & 25 & $20^{1}$ & $6(1)$ & 6 \\
\end{tabular}

Figures in parentheses indicate dropouts because of adverse effects.

${ }^{1}$ Statistics were done for 19 patients as 1 patient had not filled out at least 1 tinnitus handicap questionnaire completely ( $>20 \%$ of items missing). 
Table 5. Sample characteristics with statistics for group differences as indicated by ANOVAs or $\chi^{2}$ tests of independence

\begin{tabular}{|c|c|c|c|c|c|c|}
\hline & $\begin{array}{l}\text { Orphen- } \\
\text { adrine }\end{array}$ & $\begin{array}{l}\text { Tizani- } \\
\text { dine }\end{array}$ & $\begin{array}{l}\text { Cyclobenzaprine } \\
\text { (high dose) }\end{array}$ & $\begin{array}{l}\text { Cyclobenzaprine } \\
\text { (low dose) }\end{array}$ & Eperisone & $\mathrm{p}$ \\
\hline Age, years & $50 \pm 12$ & $51 \pm 10$ & $55 \pm 11$ & $55 \pm 10$ & $49 \pm 10$ & 0.435 \\
\hline Females/males & $13 / 5$ & $6 / 5$ & $8 / 7$ & $3 / 9$ & $5 / 14$ & 0.030 \\
\hline Tinnitus duration, months & $99 \pm 85$ & $55 \pm 59$ & $172 \pm 148$ & $147 \pm 107$ & $66 \pm 79$ & 0.010 \\
\hline Number of previous treatments $(0 / 1 />1)$ & $3 / 6 / 9$ & $4 / 1 / 6$ & $0 / 2 / 12$ & $0 / 1 / 11$ & $0 / 0 / 19$ & 0.001 \\
\hline Tinnitus laterality (bilateral and head/unilateral) & $7 / 11$ & $7 / 4$ & $10 / 5$ & $8 / 4$ & $13 / 6$ & 0.347 \\
\hline Somatic modulation of tinnitus (no/yes/don't know) & $14 / 3 / 1$ & $10 / 1 / 0$ & $10 / 5 / 0$ & $7 / 5 / 0$ & $9 / 10 / 0$ & 0.167 \\
\hline Suffering from neck pain (yes/no) & $9 / 9$ & $3 / 7$ & $4 / 11$ & $4 / 7$ & $1 / 18$ & 0.051 \\
\hline Minimal masking level, dB HL & $48 \pm 18$ & $45 \pm 16$ & $46 \pm 15$ & $53 \pm 18$ & $55 \pm 22$ & 0.678 \\
\hline Mean hearing level, dB HL & $27 \pm 14$ & $24 \pm 14$ & $32 \pm 10$ & $28 \pm 26$ & $16 \pm 12$ & 0.126 \\
\hline
\end{tabular}

Figures are numbers or means $\pm \mathrm{SD}$.

The main outcome measurement was the difference in the THI score between week 12 and baseline in the intention-to-treat sample. That means that missing data were replaced by the last observation carried forward and backward approach in data sets with at least 1 THI score. For the primary outcome paired Student $t$ tests for the particular treatment groups were performed including effect sizes (d) according to Cohen [1988]. As the five treatment groups were independent and also from different centers, analyses including all treatment groups and comparisons between treatment groups were marked as explorative. In explorative analyses, baseline-corrected THI scores at week 12 (baseline minus week 12) were compared by an analysis of variance (ANOVA) with the between-subjects factor 'treatment group'. The same ANOVA was done for CGI, which was used as a secondary outcome variable. Additionally, $\chi^{2}$ tests of independence for the variables 'treatment group' and 'positive treatment response' were calculated. According to recent findings, positive response was defined as a minimum THI change of 7 points [Zeman et al., 2011]. Furthermore, an ANOVA with the between-subjects factor 'treatment group' and the within-subjects factor 'time' (7 levels: screening, baseline, week 2 , week 4 , week 8 , week 12 , week 16) was performed.

Treatment groups were compared at baseline for age, gender, tinnitus laterality, tinnitus duration, mean hearing level, minimal masking level, number of previous treatments, somatic modulation of tinnitus and suffering from neck pain, by separate ANOVAs or $\chi^{2}$ tests. Whenever differences across groups were observed $(\mathrm{p}<0.2)$, the potential influences of these parameters on treatment outcome were evaluated by correlation analyses, ANOVAs or $\chi^{2}$ tests.

\section{Results}

\section{Tolerability and Side Effects}

The total numbers of subjects screened, those allocated to treatment, and those completing treatment, are given in table 4 . The sample characteristics for each treatment are shown in table 5 .
Reported adverse effects differed according to the administered treatment. Patients of the high-dose cyclobenzaprine group complained of dry mouth, sleepiness and constipation. One subject suffered from severe constipation, and treatment was stopped at week 8. Low-dose cyclobenzaprine patients reported dry mouth, weight gain, tiredness, constipation, hypertension (1 dropout), cardiac long Q-T interval syndrome (1 dropout), gout, urinary retention, reflux, sexual dysfunction, dizziness, lightheadedness and increased tinnitus (1 dropout). Beside the 3 patients mentioned above with the declaration of particular dropout reasons, 3 additional patients stopped treatment because of several adverse events (2 patients) or without specification of reasons (1 patient). Patients receiving orphenadrine mentioned dry mouth, hand tremor, gastric discomfort, nausea, dizziness and somnolence. In 5 patients treatment was stopped because of adverse effects, and in all cases side effects disappeared after the drug had been suspended. In the tizanidine group, side effects were frequent and responsible for most of the dropouts (5/11). They included: sleepiness, dizziness, dry mouth, visual hallucination, weakness, agitation, insomnia cramps and hypotension. All subjects immediately recovered when medication was removed. Eperisone side effects were headache, tiredness, sexual dysfunction, insomnia, agitation, hypertension, elevated liver enzymes and increased tinnitus (1 dropout). One additional patient stopped treatment because of lack of improvement and 4 further patients dropped out without specification of reasons.

\section{Primary Outcome}

High-dose cyclobenzaprine $(\mathrm{T}=6.8$; d.f. $=12 ; \mathrm{p}<$ $0.001 ; \mathrm{d}=1.742)$ but not low-dose cyclobenzaprine $(\mathrm{T}=$ 
Fig. 1. THI scores for all treatment groups and all time points.

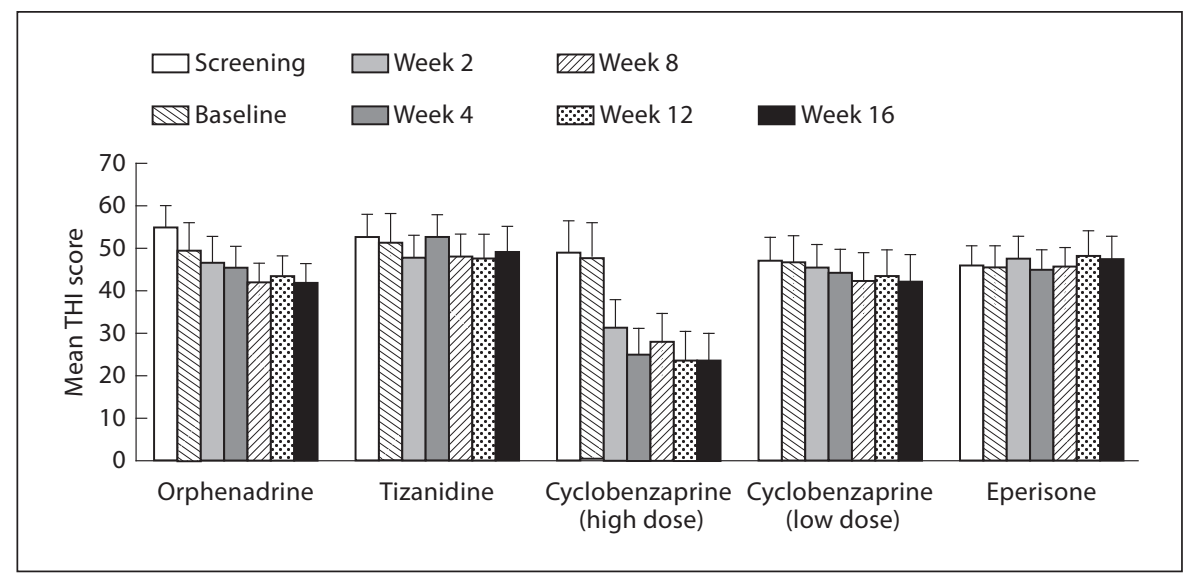

1.1; d.f. $=11 ; \mathrm{p}=0.281 ; \mathrm{d}=0.121$ ) resulted in a significant reduction in THI score from baseline to week 12 . Neither orphenadrine $(\mathrm{T}=1.7$; d.f. $=17 ; \mathrm{p}=0.117 ; \mathrm{d}=0.427)$ nor tizanidine $(\mathrm{T}=2.0$; d.f. $=10 ; \mathrm{p}=0.080 ; \mathrm{d}=0.161)$ nor eperisone ( $\mathrm{T}=0.9$; d.f. $=18 ; \mathrm{p}=0.377 ; \mathrm{d}=0.087$ ) showed a significant reduction of THI scores. Overall THI effects are depicted in figure 1.

\section{Explorative Analyses}

The ANOVA for baseline-corrected THI change at week 12 showed a significant treatment group main effect $(\mathrm{F}=8.9 ;$ d.f. $=4.70 ; \mathrm{p}<0.001)$. Bonferroni-corrected post hoc tests indicated a more pronounced THI reduction for high-dose cyclobenzaprine compared to all other medications (orphenadrine: $\mathrm{p}=0.005, \mathrm{~d}=1.048$; tizanidine: $\mathrm{p}=0.004, \mathrm{~d}=1.731$; eperisone: $\mathrm{p}<0.001, \mathrm{~d}=2.115$; lowdose cyclobenzaprine: $\mathrm{p}=0.001, \mathrm{~d}=1.719)$. All other post hoc contrasts were not significant. Differences in treatment outcome were confirmed by comparison of the number of responders $\left(\chi^{2}=24.1\right.$; d.f. $=4$; $\left.p<0.001\right)$. Highdose cyclobenzaprine had a higher number of treatment responders (14 out of 15) compared to all other treatment groups (orphenadrine: 7 out of 18; tizanidine: 4 out of 11; eperisone: 2 out of 19; low-dose cyclobenzaprine: 5 out of 12). Individual THI variation scores from baseline to week 12 are described in figure 2.

The ANOVA for CGI revealed a significant main effect of treatment group $(\mathrm{F}=6.7$; d.f. $=4.57 ; \mathrm{p}<0.001)$. Bonferroni-corrected post hoc tests indicated a more pronounced improvement for high-dose cyclobenzaprine compared to eperisone $(\mathrm{p}<0.001)$ and low-dose cyclobenzaprine $(p=0.020)$. In this analysis orphenadrine was also superior to eperisone $(p=0.026)$. All other post hoc contrasts were not significant.

Reduction of Tinnitus Severity by Cyclobenzaprine

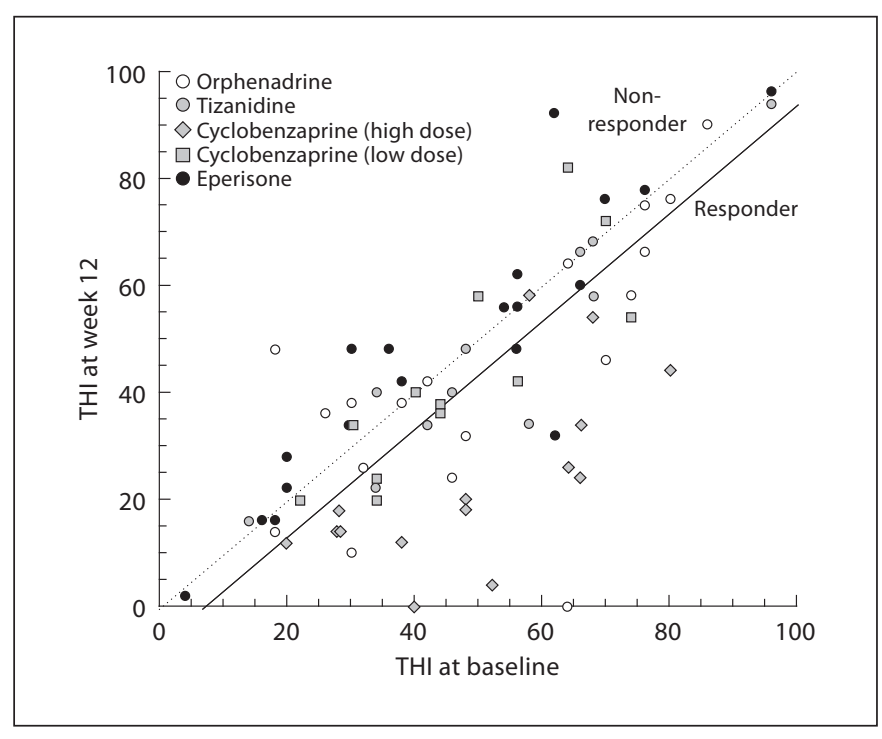

Fig. 2. Individual THI scores at baseline and at week 12. Dotted line $=$ No change in THI; continuous line $=$ response rate indicated by a reduction of at least 7 points in the THI scores from baseline to week 12 .

The ANOVA for all time points and for the THI showed a significant time-by-treatment group interaction effect $(\mathrm{F}=5.2$; d.f. $=24,420 ; \mathrm{p}<0.001)$. Bonferronicorrected post hoc tests demonstrated that the high-dose cyclobenzaprine lowered THI scores for week 2, week 4, week 8 , week 12 and week 16 in contrast to screening and baseline (all p values $<0.009$ ). All other treatments showed no significant within-group differences between the separate time points. Post hoc between-group contrasts showed treatment effects for high-dose cyclobenzaprine

Audiol Neurotol 2012;17:179-188 
compared to tizanidine $(\mathrm{p}=0.011)$ at week 4 , and compared to eperisone at week $12(\mathrm{p}=0.025)$ and at week 16 $(\mathrm{p}=0.032)$.

Groups were comparable for age, minimal masking level and tinnitus laterality. Groups were not comparable $(p<0.2)$ for gender, tinnitus duration, mean hearing lev$\mathrm{el}$, number of previous treatments, somatic modulation of the tinnitus and suffering from neck pain (table 5).

Analyses indicated no influence of tinnitus duration and mean hearing level on medication effects. In none of the treatment groups were correlations between baselinecorrected THI change at week 12 (baseline minus week 12) and tinnitus duration $(-0.214<\mathrm{r}$ values $<0.045$; all $\mathrm{p}$ values $>0.378)$ significant, nor were the correlations between baseline-corrected THI change at week 12 and mean hearing levels $(-0.249<\mathrm{r}$ values $<0.186$; all $\mathrm{p}$ values $>0.371)$. Gender had no effect on treatment outcome either (baseline-corrected THI change), as unpaired Student $t$ tests between females and males indicated no significant differences for all treatment groups (all $\mathrm{T}$ values $<1.4$; all $\mathrm{p}$ values $>0.190$ ). The same was found for somatic modulation of tinnitus (all $\mathrm{T}$ values $<1.3$; all $\mathrm{p}$ values $>0.326$ ) and for suffering from neck pain (all $\mathrm{T}$ values $<1.5$; all $\mathrm{p}$ values $>0.167$ ), except for the low-dose cyclobenzaprine group. In this group patients with neck pain had a higher benefit from cyclobenzaprine than those without neck pain $(\mathrm{T}=2.3$; d.f. $=9 ; \mathrm{p}=0.048)$. An ANOVA with the between-group factors 'number of previous treatments' $(0,1$ and $>1)$ and 'treatment groups' indicated no significant main $(\mathrm{F}=1.8$; d.f. $=2.62 ; \mathrm{p}=0.171)$ or interaction effect $(\mathrm{F}=0.8 ;$ d.f. $=4.62 ; \mathrm{p}=0.551)$ for the number of previous treatments.

\section{Discussion}

The main finding of the present work is that the muscle relaxant cyclobenzaprine, at a dose of $30 \mathrm{mg} /$ day, reduced tinnitus severity in a group of tinnitus patients. On the other hand, a low dose of cyclobenzaprine $(10 \mathrm{mg})$ as well as the muscle relaxants tizanide, orphenadrine and eperisone were not effective. The effect of the high dose of cyclobenzaprine on tinnitus severity was significant when analyzing the primary outcome measurement, the difference in the THI score between week 12 and baseline, in the intention-to-treat sample. These results were confirmed in the explorative analysis where baselinecorrected THI scores at week 12 were compared between groups. Moreover, the comparison of the number of responders gave higher numbers for high-dose cyclobenza- prine than for each one of the other treatments. Enhanced effects of high-dose cyclobenzaprine over low-dose cyclobenzaprine and eperisone were also observed when analyzing the secondary outcome measurement, the changes in CGI.

The fact that the cyclobenzaprine low-dose treatment had no beneficial response might indicate that effective concentrations of cyclobenzaprine are not achieved with lower doses of cyclobenzaprine. This is similar to what has been described for pain disorders, where a $30 \mathrm{mg} /$ day dosing regimen of cyclobenzaprine is pharmacologically effective [Browning et al., 2001; Landy et al., 2011; Malanga et al., 2009]. The observation that fewer side effects and fewer dropouts were reported by patients in the cyclobenzaprine high-dose trial when compared to low-dose cyclobenzaprine might reflect the fact that the drug was effective in reducing tinnitus in the former and therefore patients disregarded side effects.

Tinnitus can result from an initial insult to the inner ear which leads to hair cell death, deafferentation and tonotopic reorganization of central auditory pathways [Eggermont, 2007; Eggermont and Roberts, 2004]. Thus, noise-induced inner ear trauma which leads to hearing loss is also one of the main known causes of tinnitus [Cacace, 2006; Elgoyhen and Langguth, 2010; Helfer et al., 2011]. Therefore, one could a priori propose that the higher the hearing loss, the more important the initial damage to the sensory auditory epithelium and therefore the higher the tinnitus severity [Mazurek et al., 2010]. In this regard, the cyclobenzaprine high-dose tinnitus group had the highest degree of hearing loss. However, this was unrelated to the severity of tinnitus since THI scores at baseline did not differ among the different groups. Moreover, the individual extent of hearing loss within the cyclobenzaprine high-dose group was not correlated with treatment response.

It has been observed that tinnitus is more resistant to treatment the longer the duration of the pathology. This has been reported for microvascular decompressions [De Ridder et al., 2004, 2007] as well as for transcranial magnetic stimulation [De Ridder et al., 2005; Kleinjung et al., 2007] and correlates with the fact that the tinnitus brain network is not static and changes with time [Schlee et al., 2009a]. The effectiveness of high-dose cyclobenzaprine is unrelated to the duration of tinnitus in affected patients since the mean duration was the longest in this group of patients and, in addition, there was no significant correlation between tinnitus duration and treatment response.

Tinnitus is not only the result of changes in the auditory pathway. Recent studies suggest that it is more com- 
plex and multimodal than originally thought [De Ridder et al., 2011; Eggermont, 2007; Eggermont and Roberts, 2004]. Thus cross-modal interactions of the somatic and auditory system in the midbrain and brainstem have been described [Dehmel et al., 2008], e.g. projections from the trigeminal nuclear complex to the cochlear nucleus [Zhou and Shore, 2004]. In this regard, tinnitus can be evoked or modulated by neural inputs coming from the somatosensory, somatomotor and visual-motor systems in some individuals [Levine et al., 2003; Sanchez et al., 2002, 2007]. In particular, the psychoacoustic parameters of tinnitus can be modulated by muscle contractions of the head, neck and limbs [Koskinen et al., 1980; Kuttila et al., 2005], pressure of myofacial trigger points [Bezerra Rocha et al., 2008; Rocha and Sanchez, 2007], cutaneous stimulation of the hand or fingerprint region and face [Cacace et al., 1999], electrical stimulation of the medial nerve and hand [Moller and Rollins, 2002], finger movements [Cullington, 2001], orofacial movements [Pinchoff et al., 1998] and pressure applied to the temporomandibular joint or lateral pterygoid muscle [Bjorne, 1993; Rubinstein, 1993]. Cyclobenzaprine is a muscle relaxant, and animal studies have shown that it activates locus coeruleus neurons, leading to an increased release of noradrenaline in the ventral horn of the spinal cord and the subsequent inhibitory action of noradrenaline on $\alpha$-motoneurons [Commissiong et al., 1981]. Thus, one could propose that the decrease in tinnitus severity observed in the high-dose cyclobenzaprine group is the result of an interaction with the somatosensory system. However, an interaction between neck pain and treatment response was only observed for the low-dose cyclobenzaprine group. In the other treatment groups there was no correlation between somatic modulation or neck pain and benefit from treatment. Moreover, the fact that the other muscle relaxants orphenadrine, tizanidine and eperisone were ineffective most likely indicates that muscle relaxation is not the underlying mechanism of the cyclobenzaprine effect. In addition, other centrally acting muscle relaxants such as flupirtine and baclofen have failed to demonstrate beneficial effects on tinnitus [Salembier et al., 2006; Westerberg et al., 1996].

The mechanism of action underlying the beneficial effect of cyclobenzaprine on tinnitus is at present unknown and cannot be inferred from the present study. The structure of cyclobenzaprine is related to that of amiptriptyline [Lofland et al., 2001], a tricyclic antidepressant. Antidepressants have long been used for the treatment of tinnitus. Due to their beneficial effects on chronic pain syndromes [Mico et al., 2006], particular interest has been paid to tricyclic antidepressants. For example, one study has compared amitriptyline with placebo and found that after 6 weeks of $100 \mathrm{mg}$ amitriptyline there is a significant reduction of tinnitus complaints and tinnitus loudness compared to the placebo group [Bayar et al., 2001]. The reason for such a large use of antidepressants can be found in the well-described comorbidity between depressive disorders and tinnitus [Langguth et al., 2011]. In most cases, relief of tinnitus is best achieved in patients with depressive symptoms [Sullivan et al., 1993]. The fact that no major depressive symptoms were described in the patients included in the study makes an antidepressant mechanism of action highly improbable as an explanation for the cyclobenzaprine effect on tinnitus, even if such an explanation cannot be entirely excluded.

The structure of cyclobenzaprine is also related to that of cyproheptadine [Honda et al., 2003], an antagonist of histamine $\mathrm{H}_{1}$ receptors, muscarinic acetylcholine receptors, and $5-\mathrm{HT}_{2 \mathrm{~A}}$ serotonin receptors [Blackshear et al., 1983; Orzechowski et al., 2005; Watemberg et al., 1999; Wolf and Schunack, 1996]. An antagonistic effect of cyclobenzaprine on $5-\mathrm{HT}_{2}$ receptors has been described [Honda et al., 2003; Kobayashi et al., 1996]. Animal studies have shown that muscarinic antagonists suppress salicylate-induced plasticity in the auditory cortex and, therefore, might be effective in suppressing the tinnitus [Wallhausser-Franke et al., 2006]. On the other hand, it has been suggested that the perception of tinnitus could be linked to a dysfunction of serotonin transmission at one or more levels in the central nervous system [Simpson and Davies, 2000] and auditory stimulus processing has been associated with serotonergic function [Gallinat et al., 2003].

Hyperactivity of the dorsal cochlear nucleus has been reported in animal models of tinnitus [Kaltenbach, 2006]. Dorsal cochlear nucleus fusiform cells receive inputs from noradrenergic neurons in the locus coeruleus [Jones and Yang, 1985; Thompson et al., 1995]. Stimulation of the locus coeruleus causes changes in the level of activity in the dorsal cochlear nucleus [Chikamori et al., 1980]. There is evidence indicating that the locus coeruleus plays a role in promoting selective attention and orientation to sensory stimuli [Aston-Jones and Bloom, 1981; Rajkowski et al., 2004]. Cyclobenzaprine decreases the spontaneous firing rate of locus coeruleus neurons [Barnes et al., 1980], which might in part explain the effects of this compound in tinnitus patients.

In summary, we report that cyclobenzaprine, at a dose of $30 \mathrm{mg} /$ day, is effective in reducing tinnitus severity. The present results and comparisons between trials 
should be taken as explorative since not all trials were performed in the same center and no placebo effect was evaluated. Moreover, further studies should assess the effect of cyclobenzaprine on subjective tinnitus loudness. However, the fact that cyclobenzaprine high-dose treatment was more efficacious than tizanidine and orphenadrine, being all three performed in the same center (thus under comparable conditions), is encouraging. Moreover, the longer tinnitus duration and the higher extent of prior treatment resistance as compared to the other groups treated at the same center (tizanidine and orphenadrine) strongly argues against a pure unspecific placebo effect as an explanation for the observed results with high-dose cyclobenzaprine. Thus, the present work sheds light onto a new drug with promising results for tinnitus treatment. Randomized, placebo-controlled, double-blind studies of the use of cyclobenzaprine on tinnitus patients should follow this open-label exploratory trial.

\section{Acknowledgements}

This work was supported by the Tinnitus Research Initiative. The authors want to thank the members of the Tinnitus Research Initiative Pharma Workgroup for their input regarding tinnitus therapeutics.

\section{References}

Abdul-Baqi KJ: Objective high-frequency tinnitus of middle-ear myoclonus. J Laryngol Otol 2004;118:231-233.

-Aston-Jones G, Bloom FE: Norepinephrine-containing locus coeruleus neurons in behaving rats exhibit pronounced responses to nonnoxious environmental stimuli. J Neurosci 1981;1:887-900.

Barnes CD, Fung SJ, Gintautas J: Brainstem noradrenergic system depression by cyclobenzaprine. Neuropharmacology 1980;19:221224.

Bauer CA, Turner JG, Caspary DM, Myers KS, Brozoski TJ: Tinnitus and inferior colliculus activity in chinchillas related to three distinct patterns of cochlear trauma. J Neurosci Res 2008;86:2564-2578.

- Bayar N, Boke B, Turan E, Belgin E: Efficacy of amitriptyline in the treatment of subjective tinnitus. J Otolaryngol 2001;30:300-303.

- Bezerra Rocha CA, Sanchez TG, Tesseroli de Siqueira JT: Myofascial trigger point: a possible way of modulating tinnitus. Audiol Neurotol 2008;13:153-160.

Bjorne A: Tinnitus aereum as an effect of increased tension in the lateral pterygoid muscle. Otolaryngol Head Neck Surg 1993;109: 969.

-Blackshear MA, Friedman RL, Sanders-Bush E: Acute and chronic effects of serotonin (5HT) antagonists on serotonin binding sites. Naunyn Schmiedebergs Arch Pharmacol 1983;324:125-129.

-Browning R, Jackson JL, O’Malley PG: Cyclobenzaprine and back pain: a meta-analysis. Arch Intern Med 2001;161:1613-1620.

- Cabitza P, Randelli P: Efficacy and safety of eperisone in patients with low back pain: a double blind randomized study. Eur Rev Med Pharmacol Sci 2008;12:229-235.

Cacace AT: Hearing loss and tinnitus prevention initiatives: partnerships for success. Am J Audiol 2006;15:99-100.
Cacace AT, Cousins JP, Parnes SM, McFarland DJ, Semenoff D, Holmes T, Davenport C, Stegbauer K, Lovely TJ: Cutaneous-evoked tinnitus. II. Review of neuroanatomical, physiological and functional imaging studies. Audiol Neurotol 1999;4:258-268.

Chau C, Barbeau H, Rossignol S: Effects of intrathecal alpha1- and alpha2-noradrenergic agonists and norepinephrine on locomotion in chronic spinal cats. J Neurophysiol 1998;79: 2941-2963.

-Chikamori Y, Sasa M, Fujimoto S, Takaori S, Matsuoka I: Locus coeruleus-induced inhibition of dorsal cochlear nucleus neurons in comparison with lateral vestibular nucleus neurons. Brain Res 1980;194:53-63.

Cohen J: Statistical Power Analysis for the Behavioral Sciences. Hillsdale, Erlbaum, 1988.

-Commissiong JW, Karoum F, Reiffenstein RJ, Neff NH: Cyclobenzaprine: a possible mechanism of action for its muscle relaxant effect. Can J Physiol Pharmacol 1981;59:37-44.

Cullington H: Tinnitus evoked by finger movement: brain plasticity after peripheral deafferentation. Neurology 2001;56:978.

Darlington CL, Smith PF: Drug treatments for tinnitus. Prog Brain Res 2007;166:249-262.

Dehmel S, Cui YL, Shore SE: Cross-modal interactions of auditory and somatic inputs in the brainstem and midbrain and their imbalance in tinnitus and deafness. Am J Audiol 2008;17:S193-S209.

- De Ridder D, Elgoyhen AB, Romo R, Langguth B: Phantom percepts: tinnitus and pain as persisting aversive memory networks. Proc Natl Acad Sci USA 2011;108:8075-8080.

-De Ridder D, Heijneman K, Haarman B, van der Loo E: Tinnitus in vascular conflict of the eighth cranial nerve: a surgical pathophysiological approach to ABR changes. Prog Brain Res 2007;166:401-411.
De Ridder D, Ryu H, Moller AR, Nowe V, Van de Heyning P, Verlooy J: Functional anatomy of the human cochlear nerve and its role in microvascular decompressions for tinnitus. Neurosurgery 2004;54:381-388, discussion 388-390.

-De Ridder D, Verstraeten E, Van der Kelen K, De Mulder G, Sunaert S, Verlooy J, Van de Heyning P, Moller A: Transcranial magnetic stimulation for tinnitus: influence of tinnitus duration on stimulation parameter choice and maximal tinnitus suppression. Otol Neurotol 2005;26:616-619.

-Desaphy JF, Dipalma A, De Bellis M, Costanza T, Gaudioso C, Delmas P, George AL Jr, Camerino DC: Involvement of voltage-gated sodium channels blockade in the analgesic effects of orphenadrine. Pain 2009;142:225235.

Dobie RA: A review of randomized clinical trials in tinnitus. Laryngoscope 1999;109:12021211.

Dohrmann K, Weisz N, Schlee W, Hartmann T, Elbert T: Neurofeedback for treating tinnitus. Prog Brain Res 2007;166:473-485.

Eggermont JJ: Pathophysiology of tinnitus. Prog Brain Res 2007;166:19-35.

Eggermont JJ, Roberts LE: The neuroscience of tinnitus. Trends Neurosci 2004;27:676-682.

-Elgoyhen AB, Langguth B: Pharmacological approaches to the treatment of tinnitus. Drug Discov Today 2010;15:300-305.

Gallinat J, Senkowski D, Wernicke C, Juckel G, Becker I, Sander T, Smolka M, Hegerl U, Rommelspacher H, Winterer G, Herrmann WM: Allelic variants of the functional promoter polymorphism of the human serotonin transporter gene is associated with auditory cortical stimulus processing. Neuropsychopharmacology 2003;28:530-532.

Goodey R: Tinnitus treatment: state of the art. Prog Brain Res 2007;166:237-246. 
- Helfer TM, Jordan NN, Lee RB, Pietrusiak P, Cave K, Schairer K: Noise-induced hearing injury and comorbidities among postdeployment US army soldiers: April 2003 through June 2009. Am J Audiol 2011;20:33-41.

Honda M, Nishida T, Ono H: Tricyclic analogs cyclobenzaprine, amitriptyline and cyproheptadine inhibit the spinal reflex transmission through $5-\mathrm{HT}_{2}$ receptors. Eur J Pharmacol 2003;458:91-99.

-Hunskaar S, Donnell D: Clinical and pharmacological review of the efficacy of orphenadrine and its combination with paracetamol in painful conditions. J Int Med Res 1991;19: 71-87.

Ishizuki M, Yanagisawa M: Antinociceptive effects of tizanidine, diazepam and eperisone in isolated spinal cord-tail preparations of newborn rat. Pain 1992;48:101-106.

-Jastreboff PJ, Jastreboff MM: Tinnitus retraining therapy: a different view on tinnitus. ORL J Otorhinolaryngol Relat Spec 2006;68: 23-29, discussion 29-30.

Jones BE, Yang TZ: The efferent projections from the reticular formation and the locus coeruleus studied by anterograde and retrograde axonal transport in the rat. J Comp Neurol 1985;242:56-92.

Kaltenbach JA: The dorsal cochlear nucleus as a participant in the auditory, attentional and emotional components of tinnitus. Hear Res 2006;216-217:224-234.

Kaltenbach JA, Godfrey DA: Dorsal cochlear nucleus hyperactivity and tinnitus: are they related? Am J Audiol 2008;17:S148-S161.

Kino Y, Tanabe M, Honda M, Ono H: Involvement of supraspinal imidazoline receptors and descending monoaminergic pathways in tizanidine-induced inhibition of rat spinal reflexes. J Pharmacol Sci 2005;99:52-60.

Kleinjung T, Steffens T, Sand P, Murthum T, Hajak G, Strutz J, Langguth B, Eichhammer P: Which tinnitus patients benefit from transcranial magnetic stimulation? Otolaryngol Head Neck Surg 2007;137:589-595.

Kobayashi H, Hasegawa Y, Ono H: Cyclobenzaprine, a centrally acting muscle relaxant, acts on descending serotonergic systems. Eur J Pharmacol 1996;311:29-35.

-Kornhuber J, Parsons CG, Hartmann S, Retz W, Kamolz S, Thome J, Riederer P: Orphenadrine is an uncompetitive $\mathrm{N}$-methyl-D-aspartate (NMDA) receptor antagonist: binding and patch clamp studies. J Neural Transm Gen Sect 1995;102:237-246.

Koskinen J, Paavolainen M, Raivio M, Roschier J: Otological manifestations in temporomandibular joint dysfunction. J Oral Rehabil 1980;7:249-254.

Kuttila S, Kuttila M, Le Bell Y, Alanen P, Suonpaa $\mathrm{J}$ : Recurrent tinnitus and associated ear symptoms in adults. Int J Audiol 2005;44: 164-170.
Landgrebe M, Langguth B, Zeman F, Koller M: Methodology of clinical trials for tinnitus; in Moller A, Langguth B, De Ridder D, Kleinjung $\mathrm{T}$ (eds): Textbook of Tinnitus. New York, Springer, 2011a, pp 199-212.

Landgrebe M, Zeman F, Koller M, Eberl Y, Mohr M, Reiter J, Staudinger S, Hajak G, Langguth B: The Tinnitus Research Initiative (TRI) database: a new approach for delineation of tinnitus subtypes and generation of predictors for treatment outcome. BMC Med Inform Decis Mak 2011b;10:42.

Landy S, Altman CA, Xie F: Time to recovery in patients with acute painful musculoskeletal conditions treated with extended-release or immediate-release cyclobenzaprine. Adv Ther 2011;28:295-303.

Langguth B, Goodey R, Azevedo A, Bjorne A Cacace A, Crocetti A, Del Bo L, De Ridder D, Diges I, Elbert T, Flor H, Herraiz C, Ganz Sanchez T, Eichhammer P, Figueiredo R, Hajak G, Kleinjung T, Landgrebe M, Londero A, Lainez MJ, Mazzoli M, Meikle MB, Melcher J, Rauschecker JP, Sand PG, Struve M, Van de Heyning P, Van Dijk P, Vergara R: Consensus for tinnitus patient assessment and treatment outcome measurement: Tinnitus Research Initiative meeting, Regensburg, July 2006. Prog Brain Res 2007;166: 525-536.

Langguth B, Hajak G, Kleinjung T, Pridmore S, Sand P, Eichhammer P: Repetitive transcranial magnetic stimulation and chronic tinnitus. Acta Otolaryngol Suppl 2006;556: 102-105.

Langguth B, Landgrebe M, Kleinjung T, Sand P, Hajak G: Tinnitus and depression. World Biol Psychiatry 2011;12:489-500.

Langguth B, Salvi R, Elgoyhen AB: Emerging pharmacotherapy of tinnitus. Expert Opin Emerg Drugs 2009; 14:687-702.

Leite FM, Atallah AN, El Dib R, Grossmann E, Januzzi E, Andriolo RB, da Silva EM: Cyclobenzaprine for the treatment of myofascial pain in adults. Cochrane Database Syst Rev 2009;3:CD006830.

Levine RA, Abel M, Cheng H: CNS somatosensory-auditory interactions elicit or modulate tinnitus. Exp Brain Res 2003;153:643-648.

Lofland JH, Szarlej D, Buttaro T, Shermock S, Jalali S: Cyclobenzaprine hydrochloride is a commonly prescribed centrally acting muscle relaxant, which is structurally similar to tricyclic antidepressants (TCAs) and differs from amitriptyline by only one double bond. Clin J Pain 2001;17:103-104.

Malanga GA, Ruoff GE, Weil AJ, Altman CA, Xie F, Borenstein DG: Cyclobenzaprine ER for muscle spasm associated with low back and neck pain: two randomized, doubleblind, placebo-controlled studies of identical design. Curr Med Res Opin 2009;25:1179_ 1196.
-Mazurek B, Olze H, Haupt H, Szczepek AJ: The more the worse: the grade of noise-induced hearing loss associates with the severity of tinnitus. Int J Environ Res Public Health 2010;7:3071-3079.

Melcher JR, Sigalovsky IS, Guinan JJ Jr, Levine RA: Lateralized tinnitus studied with functional magnetic resonance imaging: abnormal inferior colliculus activation. J Neurophysiol 2000;83:1058-1072.

-Mico JA, Ardid D, Berrocoso E, Eschalier A: Antidepressants and pain. Trends Pharmacol Sci 2006;27:348-354.

Moller AR: Tinnitus: presence and future. Prog Brain Res 2007a;166:3-16.

Moller AR: Tinnitus and pain. Prog Brain Res 2007b;166:47-53.

Moller AR, Rollins PR: The non-classical auditory pathways are involved in hearing in children but not in adults. Neurosci Lett 2002;319:41-44.

Murai K, Tyler RS, Harker LA, Stouffer JL: Review of pharmacologic treatment of tinnitus. Am J Otol 1992;13:454-464.

Drzechowski RF, Currie DS, Valancius CA: Comparative anticholinergic activities of 10 histamine $\mathrm{H}_{1}$ receptor antagonists in two functional models. Eur J Pharmacol 2005; 506:257-264.

Patterson MB, Balough BJ: Review of pharmacological therapy for tinnitus. Int Tinnitus J 2006;12:149-159.

Pinchoff RJ, Burkard RF, Salvi RJ, Coad ML, Lockwood AH: Modulation of tinnitus by voluntary jaw movements. Am J Otol 1998; 19:785-789.

Rajkowski J, Majczynski H, Clayton E, AstonJones G: Activation of monkey locus coeruleus neurons varies with difficulty and performance in a target detection task. J Neurophysiol 2004;92:361-371

$>$ Rocha CA, Sanchez TG: Myofascial trigger points: another way of modulating tinnitus. Prog Brain Res 2007;166:209-214.

Rubinstein B: Tinnitus and craniomandibular disorders - is there a link? Swed Dent J Suppl 1993;95:1-46

- Salembier L, De Ridder D, Van de Heyning PH: The use of flupirtine in treatment of tinnitus. Acta Otolaryngol Suppl 2006;556:93-95.

-Sanchez TG, da Silva Lima A, Brandao AL, Lorenzi MC, Bento RF: Somatic modulation of tinnitus: test reliability and results after repetitive muscle contraction training. Ann Otol Rhinol Laryngol 2007;116:30-35.

-Sanchez TG, Guerra GC, Lorenzi MC, Brandao $\mathrm{AL}$, Bento RF: The influence of voluntary muscle contractions upon the onset and modulation of tinnitus. Audiol Neurotol 2002;7:370-375.

-Sayers AC, Burki HR, Eichenberger E: The pharmacology of 5-chloro-4-(2-imidazolin-2yl-amino)-2,1,3-benzothiadiazole (DS 103282), a novel myotonolytic agent. Arzneimittelforschung 1980;30:793-803. 
- Schlee W, Hartmann T, Langguth B, Weisz N: Abnormal resting-state cortical coupling in chronic tinnitus. BMC Neurosci 2009a;10: 11.

-Schlee W, Mueller N, Hartmann T, Keil J, Lorenz I, Weisz N: Mapping cortical hubs in tinnitus. BMC Biol 2009b;7:80.

-Schlee W, Weisz N, Bertrand O, Hartmann T, Elbert T: Using auditory steady state responses to outline the functional connectivity in the tinnitus brain. PLoS One 2008;3:e3720.

- Simpson JJ, Davies WE: A review of evidence in support of a role for 5-HT in the perception of tinnitus. Hear Res 2000;145:1-7.

- Smits M, Kovacs S, de Ridder D, Peeters RR, van Hecke P, Sunaert S: Lateralization of functional magnetic resonance imaging (fMRI) activation in the auditory pathway of patients with lateralized tinnitus. Neuroradiology 2007;49:669-679.
Sullivan M, Katon W, Russo J, Dobie R, Sakai C: A randomized trial of nortriptyline for severe chronic tinnitus. Effects on depression, disability, and tinnitus symptoms. Arch Intern Med 1993;153:2251-2259.

Thompson AM, Moore KR, Thompson GC: Distribution and origin of serotoninergic afferents to guinea pig cochlear nucleus. J Comp Neurol 1995;351:104-116.

-Van de Heyning P, Vermeire K, Diebl M, Nopp $\mathrm{P}$, Anderson I, De Ridder D: Incapacitating unilateral tinnitus in single-sided deafness treated by cochlear implantation. Ann Otol Rhinol Laryngol 2008;117:645-652.

Vio MM, Holme RH: Hearing loss and tinnitus: 250 million people and a US $\$ 10$ billion potential market. Drug Discov Today 2005; 10 : 1263-1265.

Wallhausser-Franke E, Cuautle-Heck B, Wenz G, Langner G, Mahlke C: Scopolamine attenuates tinnitus-related plasticity in the auditory cortex. Neuroreport 2006;17:14871491.

Watemberg NM, Roth KS, Alehan FK, Epstein CE: Central anticholinergic syndrome on therapeutic doses of cyproheptadine. Pediatrics 1999; 103:158-160.
Westerberg BD, Roberson JB Jr, Stach BA: A double-blind placebo-controlled trial of baclofen in the treatment of tinnitus. Am J Otol 1996; 17:896-903.

Wolf C, Schunack W: Synthesis and pharmacology of combined histamine $\mathrm{H}_{1}-/ \mathrm{H}_{2}$-receptor antagonists containing diphenhydramine and cyproheptadine derivatives. Arch Pharm (Weinheim) 1996;329:87-94.

Yang M, Zhou M, He L, Chen N, Zakrzewska JM: Non-antiepileptic drugs for trigeminal neuralgia. Cochrane Database Syst Rev 2011; 1:CD004029.

Zeman F, Koller M, Figueiredo R, Aazevedo A, Rates M, Coelho C, Kleinjung T, de Ridder D, Langguth B, Landgrebe M: Tinnitus handicap inventory for evaluating treatment effects: which changes are clinically relevant? Otolaryngol Head Neck Surg 2011;145: 282-287.

Zhou J, Shore S: Projections from the trigeminal nuclear complex to the cochlear nuclei: a retrograde and anterograde tracing study in the guinea pig. J Neurosci Res 2004;78:901-907. 